\title{
Percepção da qualidade em serviços públicos de saúde: um estudo de caso*
}

\author{
Marianella Aguilar Ventura Fadel** \\ Gilsée Ivan Regis Filho***
}

SumÁrio: 1. Introdução; 2. Gestão pela qualidade; 3. Qualidade em serviços de saúde; 4. Metodologia; 5. Resultados e discussão; 6. Conclusões.

Summary: 1. Introduction; 2. Public administration through quality; 3. Quality in the healthcare services; 4. Methodology; 5. Results and discussion; 6. Conclusion.

Palavras-chave: qualidade; serviço público de odontologia; percepção da qualidade.

KEY WoRDs: quality; dental public services; quality perception.

A literatura científica apresenta de forma significativa a importância da qualidade em serviços, e como as empresas e os serviços públicos devem atuar para alcançar a excelência na prestação desses serviços. A percepção da qualidade baseia-se em critérios objetivos e subjetivos. Conhecer a percepção dos clientes internos (funcionários) e externos (usuários), a respeito da qualidade do serviço público, pode ser um primeiro passo para o desenvolvimento de ações que levarão a melhorias, tanto por parte do gestor do sistema, que precisa conhecer o entendimento de ambos os clientes para poder melhor direcionar suas estratégias e ações, como por parte dos próprios profissionais que, entendendo a percepção da qualidade sob a perspectiva de seus clientes, estarão mais preparados para atender suas expectativas. Este artigo investiga a percepção da qualidade de

\footnotetext{
* Artigo recebido em maio 2007 e aceito em jun. 2008.

** Doutoranda em odontologia em saúde coletiva pela Universidade Federal de Santa Catarina (UFSC), mestre em odontologia em saúde coletiva pela UFSC, professora do Curso de Graduação em Odontologia da UFSC - Clínica Integrada. Endereço: Rua Lauro Linhares, 1288, B3, 102 — Trindade — CEP 88036-002, Florianópolis, SC, Brasil. E-mail: mavfadel@terra.com.br; maya@ccs.ufsc.br.

*** Doutor e mestre em engenharia da produção pela Universidade Federal de Santa Catarina (UFSC), especialista em saúde pública. Professor do Curso de Graduação em Odontologia da UFSC - Ergonomia. E-mail: gregis@brturbo.com.br.
} 
clientes e de profissionais em serviços públicos municipais de saúde. Observouse que as categorias possuem diferenças e semelhanças a respeito da percepção dos fatores determinantes da qualidade em serviços de odontologia descritos na literatura científica. Para os profissionais a qualidade técnica dos serviços teve grande relevância, obtendo $100 \%$ das respostas. Por outro lado, para os clientes externos a qualidade é percebida pelas evidências da qualidade interpessoal observada através das condições sob as quais o cuidado é prestado e pela maneira como esses clientes são tratados pelos profissionais.

\section{Quality perception in public health services: a case study}

Scientific literature stresses the importance of quality in services and how healthcare providers and public services should act to achieve excellence. The perception towards quality is based upon subjective and objective criteria. Being aware of the perception of internal (employees) and external (users) clients regarding the quality of the public service provided can be the first step for the development of actions which will lead to some improvement. This is made by the health system administrator, who needs to get to know both types of client perception to better direct his or her strategies and actions, and by the professionals themselves, who will be more prepared to answer their clients' expectations by understanding quality through their clients' perspective. This article investigates the quality perception of health professionals and users in Brazilian municipal public health services. The study detected some disparities and similarities about determinant factors for quality described in the literature. For health professionals, the technical quality is very important, accounting for $100 \%$ of answers, whereas for external clients this is perceived through the interpersonal quality aspects revealed by how health care is provided and how they are treated by the professionals.

\section{Introdução}

Os principais problemas enfrentados nas organizações de saúde têm sido a má alocação dos recursos, a ineficiência, os custos crescentes e a desigualdade nas condições de acesso dos usuários. A melhoria das condições de saúde de grupos sociais ou de uma população pode contribuir para o crescimento econômico de diversas formas, como: reduzir as perdas de produção causadas por doença do trabalhador; permitir o uso de recursos humanos que não estiveram total ou parcialmente acessíveis por motivo de doença; aumentar o número de crianças matriculadas em escolas, o que as torna mais aptas a estudar e liberar recursos que, uma vez não aplicados em organizações de saúde, podem ter outro destino (Lima, 1998).

A demanda crescente da sociedade em relação a serviços de qualidade gerou uma necessidade de mudanças nas características destes e maior exi- 
gência para com os fornecedores de diversos tipos de serviços, inclusive os voltados à área de saúde (Vasconcellos, 2002).

Para Munro (1994), a prestação de serviços realizada pelo poder público ainda mantém em foco a própria existência do serviço, deixando sua qualidade relegada a um segundo plano. As organizações do setor público são as maiores prestadoras de bens e serviços à comunidade, que está dependente da qualidade, agilidade e localização desses serviços, tendo como principal característica uma relação de responsabilidade direta com a sociedade, necessitando continuadamente redefinir sua missão (Estefano, 1996).

A qualidade nas organizações de saúde pode ser interpretada e representada como a expressão de certas formações subjetivas: preocupação constante em criar e manter entre todos os que estão ocupados nas organizações de saúde, administradores e funcionários, o entendimento quanto à estrutura e ao processo das intervenções; e preocupação quanto aos resultados para satisfazer as necessidades emergentes e as demandas explícitas dos clientes usuários. Finalmente, a administração da qualidade das organizações de saúde tem como resultados esperados a melhoria da eficiência com eficácia e a melhoria no uso dos recursos (Lima, 1998).

Para Ansuj, Zenckner e Godoy (2005), o mais importante no julgamento da qualidade em odontologia, na concepção dos pacientes, está baseado mais nos aspectos pessoais do que na parte técnica do profissional, o que não significa que o profissional não deva preocupar-se com a qualidade técnica, pois esta é uma exigência da profissão. Para os autores, é necessário considerar os dois componentes da qualidade que, segundo Las Casas (1999), são: o serviço propriamente dito e a forma como ele é percebido pelo cliente.

Portanto, a qualidade dos serviços pode ser percebida pelos clientes por meio dos seus componentes tangíveis e intangíveis. A tangibilidade de um serviço é aquilo que o cliente vê e sente, como a aparência física do local de trabalho. Os componentes intangíveis são amabilidade e cordialidade da equipe de odontologia, ou seja, os que estão diretamente ligados ao relacionamento da equipe profissional com os clientes (Ansuj, Zenckner e Godoy, 2005).

Este artigo teve como objetivo geral investigar a percepção da qualidade de um serviço público de odontologia e, como objetivos específicos, investigar a percepção da qualidade pelos clientes, a percepção da qualidade pelos profissionais cirurgiões-dentistas e identificar os aspectos tangíveis e intangíveis associados com qualidade pelos clientes e pelos cirurgiões-dentistas.

Por outro lado, por opção metodológica, não foram pesquisados aspectos relativos aos motivos de escolha do serviço pelos clientes, nem se preten- 
deu definir um instrumento de avaliação ou medir a satisfação de usuários com os serviços.

\section{Gestão pela qualidade}

Como valor, a qualidade está associada a um estilo de gestão, à visão sistêmica, à melhoria contínua e visa promover mudanças sucessivas utilizando-se de novas técnicas de produção, voltadas ao combate dos desperdícios humanos e materiais. Compreende princípios, metodologias e ferramentas da qualidade, essenciais nas organizações.

Para Paladini (2000), é possível afirmar que qualidade é um conceito dinâmico, ou seja, que trabalha com referenciais que mudam ao longo do tempo e, às vezes, de forma bastante acentuada. Qualidade é, também, um termo de domínio público, pois todos têm uma noção intuitiva do que seja qualidade.

A qualidade é definida pelo cliente e transcende os parâmetros dos produtos, contemplando aspectos relacionados com o meio ambiente e com as relações humanas. A função qualidade e o termo cliente devem ser entendidos de forma abrangente e devem ser estendidos, também, para as relações profissionais, sociais e familiares (Neves e Neves, 2000).

Para Vasconcellos (2002), a diferença fundamental ao se definir qualidade na prestação de serviços encontra-se na subjetividade e na dificuldade de estabelecer o que é qualidade, uma vez que os clientes reagem diferentemente ao que parece ser o mesmo serviço. Cada cliente possui uma determinada percepção sobre qualidade e, muitas vezes, esta diferença implica até mesmo "estado de espírito do cliente" no momento da prestação de serviço. As pessoas possuem diferentes padrões de qualidade em diferentes momentos de sua vida.

Certamente, gerenciar serviços é diferente de gerenciar produção de bens, pois serviços são intangíveis, ou seja, não podem ser possuídos, mas vivenciados, e por isso são de difícil padronização. Necessitam da presença e da participação do cliente, o que restringe o tempo de atendimento, são personalizados, podendo ainda necessitar do treinamento do cliente; e implicam produção e consumo simultâneos, por não poderem ser estocados, dificultando sua inspeção e controle de qualidade. Por tudo isso, o processo de prestação do serviço pode ser muito mais importante que o seu próprio resultado (Gianesi e Côrrea, 1996).

A intangibilidade dos serviços, juntamente com a necessidade da presença do cliente e a simultaneidade da produção e consumo do serviço, forma 
as principais características especiais das operações em serviços, que irão definir a avaliação dos resultados e a qualidade dos serviços prestados. Entretanto, muitas vezes, essa avaliação é dificultada pela intangibilidade, uma vez que é difícil a padronização dos serviços, tornando a gestão do processo mais complexa (Gianesi e Corrêa, 1996).

Portanto, em serviços é fundamental que se controle ou realimente os processos em função das necessidades dos clientes. Em serviços são enfatizadas as relações diretas com os clientes e o processo deve ser flexível, porque o cliente participa do processo produtivo de forma efetiva e assim as organizações precisam ser flexíveis e possuir capacidade para mudança e renovação constantes (Paladini, 1995).

Grönroos (1990) afirma que os consumidores escolhem prestadores de serviços comparando as percepções que têm do serviço recebido com o serviço esperado, o que é chamado de qualidade de serviço percebida. Bons resultados na qualidade percebida são obtidos quando os serviços recebidos ou experimentados atendem às expectativas dos clientes. $\mathrm{O}$ autor conclui que somente quando o prestador de serviços entender como os serviços serão avaliados pelos clientes é que será possível saber como gerenciar tais avaliações e como influenciá-las na direção desejada.

Zeithaml, Parasuraman e Berry (1990) atribuem à qualidade de serviços a discrepância que existe entre as expectativas e as percepções dos clientes sobre um serviço experimentado. A chave para assegurar uma boa qualidade de serviço é obtida quando as percepções dos clientes excedem suas expectativas. Porém, não basta compreender a importância de se fornecer serviços com excelente qualidade, é preciso que haja um processo contínuo de monitoração das percepções dos clientes sobre a qualidade do serviço, identificação das causas das discrepâncias encontradas e adoção de mecanismos adequados para a melhoria.

De acordo com Vuori (1991), qualidade denota um grande espectro de características desejáveis de cuidado, que incluem: efetividade, eficácia, equidade, aceitabilidade, acessibilidade, adequação e qualidade técnico-científica.

Por outro lado, para Vieira e colaboradores (2000), ainda não há um corpo de conhecimento bem estabelecido sobre como as técnicas de administração da qualidade podem ser aplicadas ao setor público. Há necessidade de pesquisa empírica, especialmente sobre a natureza das mudanças nos princípios de qualidade para que possam ser aplicados com sucesso ao setor público, bem como na identificação de elementos que possam contribuir para o aperfeiçoamento do conceito de qualidade nas organizações públicas. 


\section{Qualidade em serviços de saúde}

Segundo Las Casas (1999), as dimensões da qualidade em serviços são:

- confiabilidade - é importante para prestar serviços de qualidade, gerada pela habilidade de fornecer o que foi prometido de forma segura e precisa;

v segurança - clientes querem dos prestadores de serviços a habilidade de transmitir segurança e confiança, caracterizada pelo conhecimento e cortesia dos funcionários;

- aspectos tangíveis - os aspectos físicos que circundam a atividade de prestação de serviço também têm sua importância como fator de influência, como instalações, equipamentos, aparência dos funcionários etc.;

v empatia - grau de cuidado e atenção pessoal dispensado aos clientes, como a capacidade de se colocar no lugar dos outros e, também, a receptividade, que é a disposição de ajudar os clientes e fornecer serviços com presteza.

Donabedian (1980) entende qualidade em três dimensões: a técnica, a interpessoal e a ambiental. A técnica se refere à aplicação, atualizada, dos conhecimentos científicos na solução do problema do paciente. A interpessoal se refere à relação que se estabelece entre o prestador de serviços e o paciente. A ambiental diz respeito às comodidades como conforto e bem-estar oferecidos ao paciente.

Os indivíduos têm seu próprio conceito de qualidade. É possível dizer que qualidade é aquilo que cada um acredita que é ou percebe que é. Portanto, é fundamental entender que antes de tudo o conceito de qualidade depende da percepção de cada um em função da cultura ou do grupo que se irá considerar (Cerqueira, 1994).

Existem características das organizações de saúde que tornam difícil internamente a avaliação dos resultados nelas obtidos. Parte-se da premissa de que seus trabalhadores fazem o melhor que pode ser feito (Vuori, 1991).

Segundo Regis Filho e Lopes (1996), o setor saúde como organização prestadora de serviços deve lançar mão de todos os recursos que viabilizem um melhor desempenho, com uma melhor satisfação, tanto dos clientes externos quanto dos internos.

Os fatores determinantes da qualidade dos serviços de odontologia, segundo Assada (2001), estão descritos no quadro. 
Fatores determinantes da qualidade em serviços de odontologia

\begin{tabular}{|c|c|c|}
\hline Fator & Conceito & Exemplos \\
\hline Tangibilidade & $\begin{array}{l}\text { Todas as evidências físicas do } \\
\text { serviço. }\end{array}$ & $\begin{array}{l}\text { Ambiente físico atraente, vestuário adequado } \\
\text { dos funcionários, comunicação impressa de fácil } \\
\text { entendimento, equipamentos de boa aparência } \\
\text { e modernos e resultados visíveis da odontologia } \\
\text { estática executada pela equipe de trabalho. }\end{array}$ \\
\hline Confiabilidade & $\begin{array}{l}\text { Habilidade de prover o serviço } \\
\text { com o desempenho prometido e } \\
\text { de forma confiável e acurada. }\end{array}$ & $\begin{array}{l}\text { Serviços executados corretamente e da } \\
\text { primeira vez, agendamentos adequados e sem } \\
\text { complicações, atendimento no horário acordado, } \\
\text { retorno imediato de contatos telefônicos e } \\
\text { cumprimento do que foi prometido ao cliente. }\end{array}$ \\
\hline $\begin{array}{l}\text { Pronto } \\
\text { atendimento }\end{array}$ & $\begin{array}{l}\text { Atenção imediata no auxílio } \\
\text { aos clientes e na execução dos } \\
\text { serviços. }\end{array}$ & $\begin{array}{l}\text { Rapidez na solução de problemas odontológicos } \\
\text { e de relacionamento, atenção na prestação de } \\
\text { informações e rapidez de resposta na correção de } \\
\text { erros. }\end{array}$ \\
\hline Competência & $\begin{array}{l}\text { Posse das habilidades e } \\
\text { conhecimentos técnicos } \\
\text { necessários à execução dos } \\
\text { serviços. }\end{array}$ & $\begin{array}{l}\text { Execução dos serviços sem necessidade de solicitar } \\
\text { orientação de outros profissionais ou de superiores, } \\
\text { capacidade de responder às dúvidas do cliente e } \\
\text { pleno domínio do assunto. }\end{array}$ \\
\hline Credibilidade & Capacidade de gerar confiança. & $\begin{array}{l}\text { Boa reputação, não pressionar o cliente a comprar, } \\
\text { preços justos e garantia dos serviços. }\end{array}$ \\
\hline Segurança & $\begin{array}{l}\text { Conhecimento e capacidade } \\
\text { de transmitir responsabilidade } \\
\text { e segurança com a isenção de } \\
\text { perigo, risco ou dúvidas. }\end{array}$ & $\begin{array}{l}\text { Tranquilidade ao utilizar os serviços do consultório, } \\
\text { com a equipe assumindo as preocupações para } \\
\text { que o cliente fique e se sinta seguro. }\end{array}$ \\
\hline Acessibilidade & Facilidade de acesso e de contato. & $\begin{array}{l}\text { Facilidade de agendamento, do contato quando } \\
\text { surgem problemas e por via telefônica, do contato } \\
\text { a qualquer hora, ou seja, atendimento nas } 24 \text { horas } \\
\text { do dia e plantões aos sábados, domingos e feriados. }\end{array}$ \\
\hline Comunicação & $\begin{array}{l}\text { Manter o cliente bem informado, } \\
\text { com linguagem adequada, } \\
\text { principalmente, a habilidade de } \\
\text { ouvir o cliente. }\end{array}$ & $\begin{array}{l}\text { Clareza no esclarecimento das dúvidas, } \\
\text { comunicação de qualquer alteração de horários } \\
\text { previamente acertados e atenção ao que o } \\
\text { cliente diz. }\end{array}$ \\
\hline $\begin{array}{l}\text { Compreensão } \\
\text { das } \\
\text { necessidades } \\
\text { do cliente }\end{array}$ & $\begin{array}{l}\text { Esforço feito para conhecer o } \\
\text { cliente e suas necessidades. }\end{array}$ & $\begin{array}{l}\text { Reconhecimento do cliente como indivíduo, } \\
\text { capacidade de identificar necessidades específicas } \\
\text { de cada cliente e flexibilidade para atender os } \\
\text { interesses dos clientes em primeiro lugar. }\end{array}$ \\
\hline
\end{tabular}

A percepção da qualidade baseia-se em critérios objetivos e subjetivos. O que se pode perceber como satisfação do usuário pelo tratamento odontológico recebido envolve mais do que um alto nível de competência técnica dos cirurgiões-dentistas (Abrams, Ayers e Petterson, 1986). 
No entanto, mesmo que as percepções de um serviço dependam de certo grau de julgamento pessoal, é importante que o profissional (prestador de serviço) objetive conhecer as expectativas de seus clientes para então buscar melhorias de desempenho que favoreçam uma percepção positiva. As melhores ideias para aprimorar os serviços vêm dos clientes que dependem dos produtos e serviços. Os clientes podem julgar a qualidade percebida dos serviços de saúde e também sugerir ideias úteis de melhoria (Slack et al., 1996).

Por outro lado, existem estudos como o de Castellanos (2002), que analisou comparativamente a satisfação do usuário com a qualidade dos serviços e a percepção gerencial dessa qualidade. Tal estudo identificou o grau de satisfação do usuário de um hospital geral com relação a uma série de atributos dos serviços oferecidos, estabelecendo sua relação com as dimensões da qualidade. Observou-se a existência de uma grande diferença entre o que o usuário identifica como qualidade nos serviços prestados pelo hospital e o que o gerente considera ser qualidade, demonstrando a existência de lacunas entre as duas percepções.

\section{Metodologia}

Este artigo é fruto de um estudo de caráter descritivo, ou seja, de uma pesquisa aplicada, quantitativa, exploratória e tipicamente de campo, que procurou, por meio de levantamento de dados, investigar a percepção da qualidade pelos cirurgiões-dentistas que trabalham na Prefeitura Municipal de Florianópolis e pelos clientes que utilizam esses serviços.

Os dados foram levantados através de questionários próprios elaborados e destinados aos clientes e profissionais, levando em consideração o diferente grau de entendimento dessas categorias.

Foram entrevistados os usuários do serviço imediatamente após a utilização do mesmo com o objetivo de se evitar que variáveis externas, como opinião de outros usuários, interferissem de uma maneira ou de outra na percepção da qualidade dos clientes.

Os questionários utilizados tinham duas perguntas objetivas e relativas para cada um dos fatores considerados determinantes da qualidade, de acordo com Assada (2001): tangibilidade, confiabilidade, pronto atendimento, competência, empatia, credibilidade, segurança, acessibilidade, comunicação e compreensão das necessidades dos clientes. 


\section{Resultados e discussão}

Foram entrevistados 82 usuários que estavam presentes nas unidades locais de saúde do município (ULS) e que obtiveram atendimento odontológico, e 45 cirurgiões-dentistas que trabalham nos consultórios odontológicos das ULS.

Para o teste das proporções foi aplicado o teste T de Student, ocorrendo significância estatística nas respostas dos dois grupos. $\mathrm{O}$ valor considerado padrão para ser significativo foi de $75 \%$. A associação existente entre os fatores $a$ e $b$ de cada grupo, correspondente a cada um dos dois itens de cada pergunta, está demonstrada pelo coeficiente de associação e foi calculada com base no valor do qui-quadrado.

A tabela apresenta a proporção de respostas de clientes e de profissionais em relação ao mesmo fator determinante da percepção da qualidade.

\section{Distribuição de frequências das respostas de clientes e profissionais} (82 clientes e 45 profissionais)

\begin{tabular}{|c|c|c|}
\hline \multirow[b]{2}{*}{ Fatores determinantes da qualidade } & \multicolumn{2}{|c|}{ Categorias } \\
\hline & $\begin{array}{c}\text { Clientes } \\
(\%)\end{array}$ & $\begin{array}{c}\text { Profissionais } \\
(\%)\end{array}$ \\
\hline \multicolumn{3}{|l|}{ Fator 1 (tangibilidade) } \\
\hline v la Ambiente físico & 84 & 89 \\
\hline V lb Equipamentos & 85 & 86 \\
\hline \multicolumn{3}{|l|}{ Fator 2 (confiabilidade) } \\
\hline V 2a Serviços bem executados & 87 & 100 \\
\hline v 2b Pontualidade & 78 & 69 \\
\hline \multicolumn{3}{|l|}{ Fator 3 (pronto atendimento) } \\
\hline 3a Agilidade e rapidez de resposta & 75 & 84 \\
\hline v 3b Atenção na prestação de informações & 77 & 84 \\
\hline \multicolumn{3}{|l|}{ Fator 4 (competência) } \\
\hline V 4a Execução de serviços com segurança & 86 & 95 \\
\hline - 4b Capacidade de responder a dúvidas do cliente & 89 & 78 \\
\hline \multicolumn{3}{|l|}{ Fator 5 (empatia) } \\
\hline V 5a Delicadeza e consideração ao prestar informações & 84 & 91 \\
\hline V 5b Preocupação e cuidado na preservação dos interesses do cliente & 83 & 66 \\
\hline \multicolumn{3}{|l|}{ Fator 6 (credibilidade) } \\
\hline V 6a Reputação dos serviços & 86 & 89 \\
\hline Vb Garantia dos serviços & 85 & 60 \\
\hline
\end{tabular}




\begin{tabular}{|c|c|c|}
\hline \multirow[b]{2}{*}{ Fatores determinantes da qualidade } & \multicolumn{2}{|c|}{ Categorias } \\
\hline & $\begin{array}{c}\text { Clientes } \\
(\%)\end{array}$ & $\begin{array}{c}\text { Profissionais } \\
(\%)\end{array}$ \\
\hline \multicolumn{3}{|l|}{ Fator 7 (segurança) } \\
\hline จ 7a Tranquilidade ao usar os serviços & 91 & 75 \\
\hline V 7 b Equipe comprometida com o bem-estar dos clientes & 90 & 82 \\
\hline \multicolumn{3}{|l|}{ Fator 8 (acessibilidade) } \\
\hline 8a Fácil agendamento & 66 & 82 \\
\hline v 8b Fácil localização & 84 & 78 \\
\hline \multicolumn{3}{|l|}{ Fator 9 (comunicação) } \\
\hline จ 9a Clareza ao esclarecer dúvidas & 91 & 89 \\
\hline v 9b Ouvir cliente com a devida atenção & 83 & 93 \\
\hline \multicolumn{3}{|l|}{ Fator 10 (compreensão das necessidades do cliente) } \\
\hline ح 10a Capacidade de identificar necessidades específicas de cada cliente & 84 & 91 \\
\hline V $10 \mathrm{~b}$ Flexibilidade para atender interesses do cliente & 83 & 60 \\
\hline
\end{tabular}

A figura 1 mostra a distribuição percentual de respostas dos clientes, onde se pode observar que os mesmos apontaram praticamente todos os fatores como significativamente determinantes da qualidade, exceto o fator 8a, referente ao fácil agendamento de consultas, que apresentou o menor percentual com $66 \%$ das respostas.

A figura 2 apresenta a distribuição percentual de respostas dos profissionais, onde se pode visualizar o cenário formado pelos valores apontados pelos profissionais como fatores determinantes da qualidade. Os profissionais assinalaram a maioria dos fatores como significativamente determinantes da qualidade, entretanto, os fatores $5 \mathrm{~b}, 6 \mathrm{~b}$ e $10 \mathrm{~b}$ foram os que apresentaram os menores percentuais de respostas. Esses fatores são referentes, respectivamente, à preocupação e ao cuidado na preservação dos interesses do cliente, à garantia dos serviços e à flexibilidade para atender os interesses dos clientes. $\mathrm{O}$ fator $2 \mathrm{a}$, referente à boa execução dos serviços, foi merecedor de $100 \%$ das respostas dos profissionais, o que demonstra a grande importância que os profissionais conferem às qualidades técnicas dos serviços, o que é confirmado por Abrams, Ayers e Petterson (1986) e Grönroos (1990). 


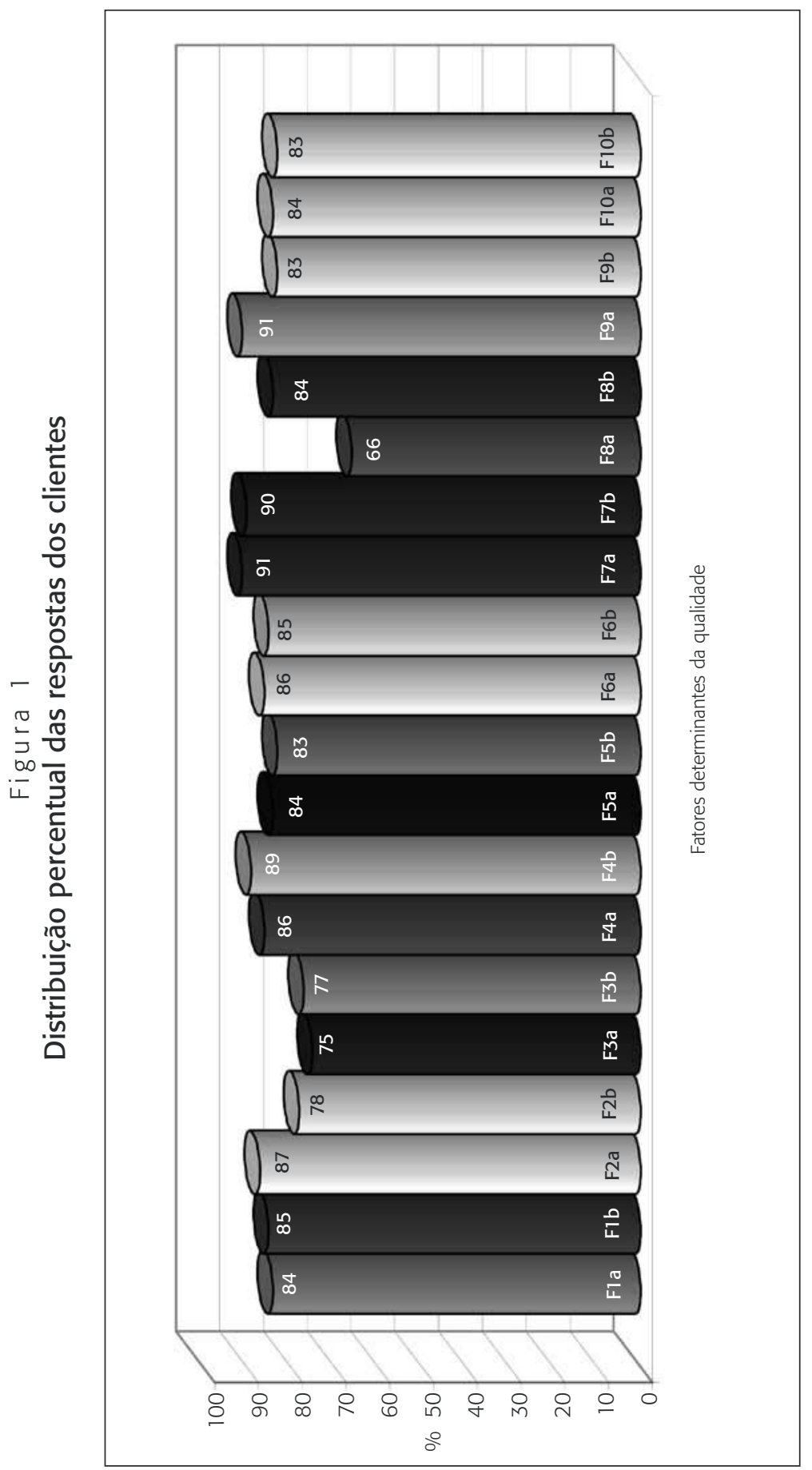

RAP - RIO DE JANEIRO 43(1):07-22, JAN./FEV. 2009 


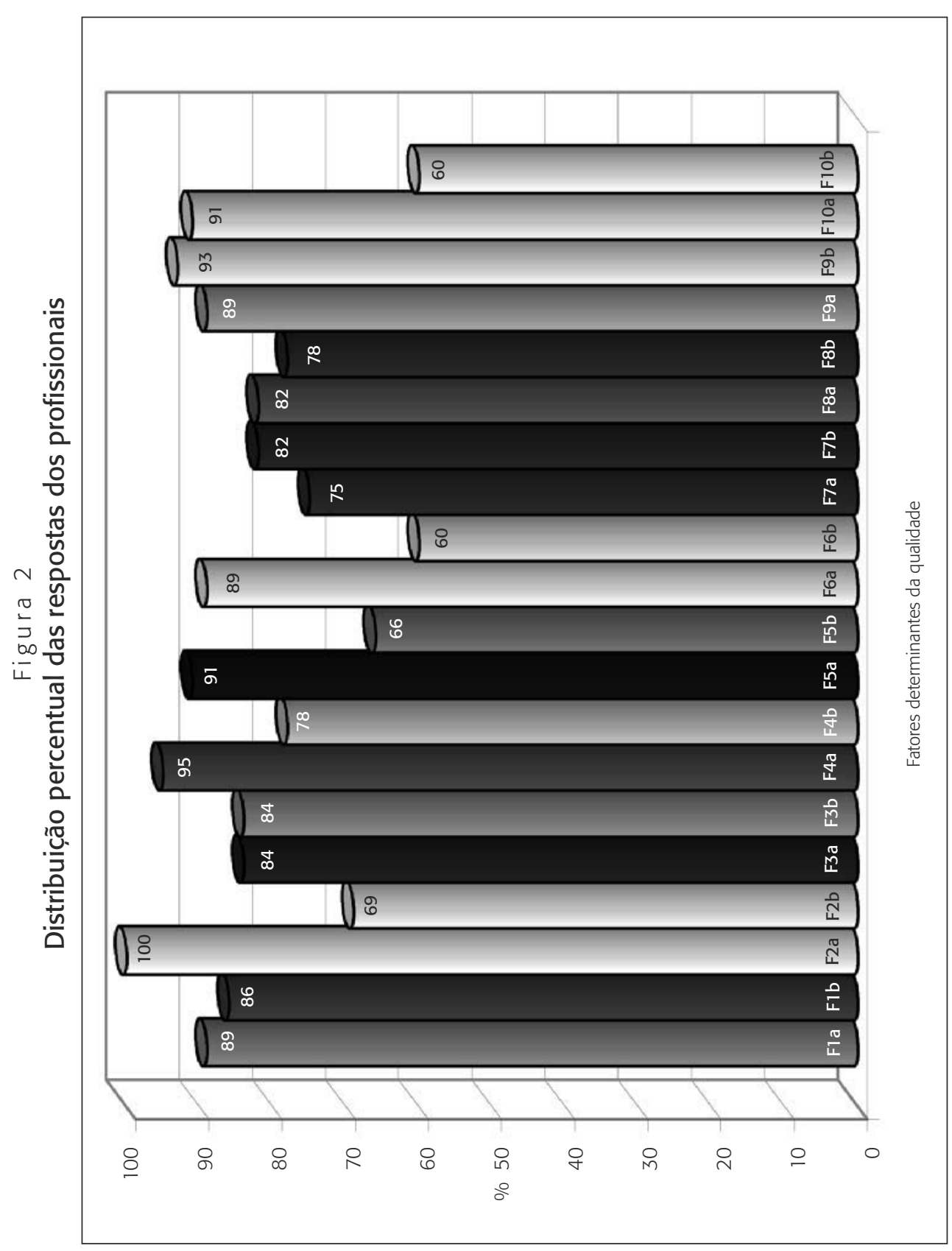


A figura 3 apresenta os valores percentuais de todos os fatores investigados nas duas categorias. É possível observar o cenário formado pelos fatores determinantes da qualidade que foram apontados pelos profissionais e pelos clientes. Assim, é possível concluir que os clientes valorizam mais os fatores da qualidade interpessoal, citada por Grönroos (1990), do que os aspectos técnicos do profissional, embora os levem em alta consideração. Isso não se contrapõe à visão dos profissionais que privilegiaram significativamente os aspectos da qualidade técnica, porém, sem deixar de levar em alta consideração os aspectos relativos à qualidade interpessoal. Portanto, na maioria dos aspectos, é possível afirmar que ambos têm percepções semelhantes do que seja um serviço odontológico público de qualidade.

Figura 3

Distribuição percentual das respostas dos clientes e dos profissionais

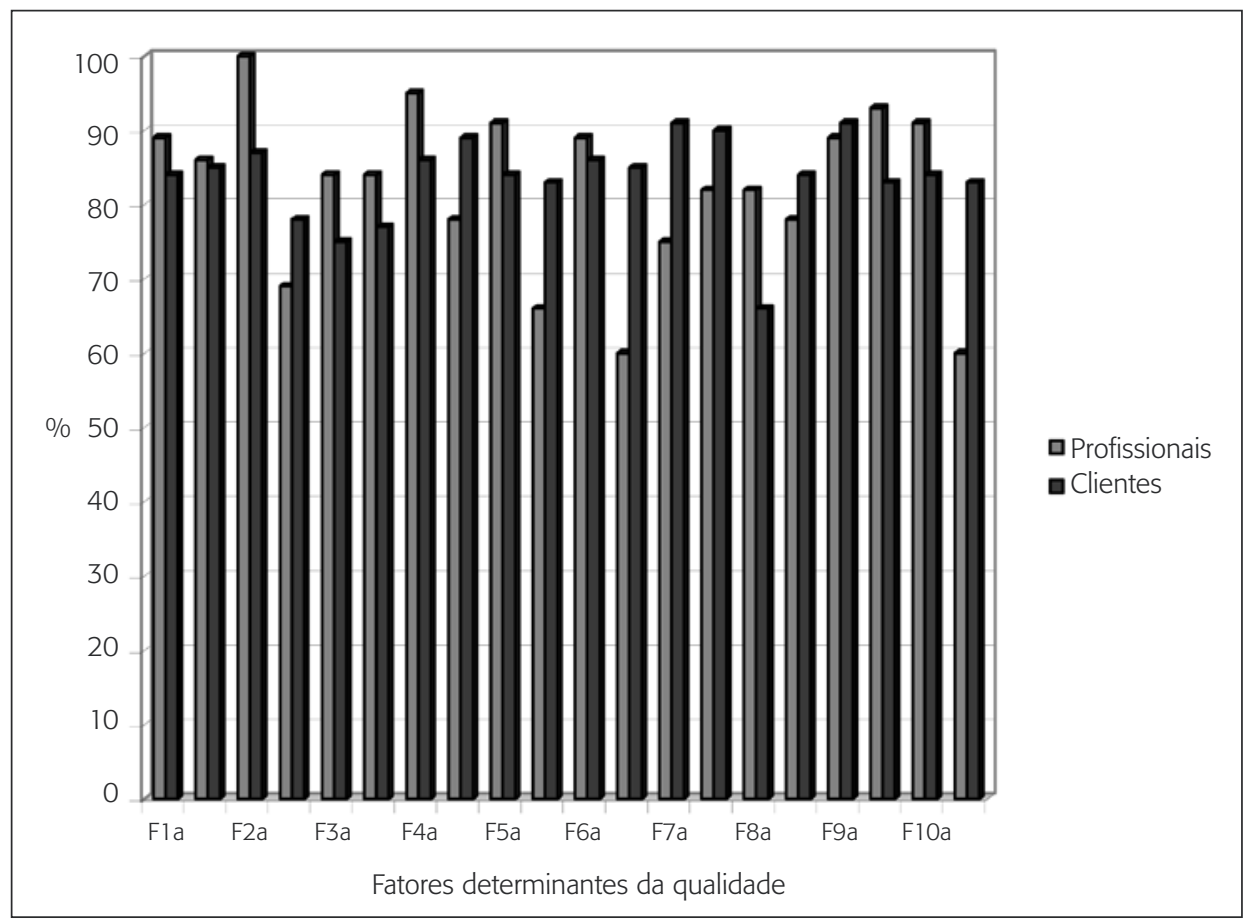

Os achados deste artigo estão em consonância com os de Castellanos (2002), onde os aspectos de maior importância para o usuário têm como dimensões predominantes a capacitação, a empatia e a confiabilidade dos pro- 
fissionais que prestam os serviços. Salienta-se que do ponto de vista da gestão de serviços de saúde o resultado é importante para que se reflita sobre o paradigma predominante no setor saúde, de que o paciente não teria condições de avaliar os aspectos técnicos dos serviços e que talvez não tenha condições de fazê-lo sob a mesma ótica dos profissionais do setor. Entretanto, o faz por meio de atributos como a educação, interesse, atenção e disponibilidade dos profissionais para com ele.

Observou-se que os aspectos mais significativos na percepção da qualidade em serviços públicos de odontologia da rede municipal de saúde de Florianópolis, para os clientes, foram: a tranquilidade ao utilizar os serviços e a clareza no esclarecimento de dúvidas (91\%) e para os cirurgiões-dentistas foi a boa execução dos serviços (100\%). De maneira geral, houve concordância nas respostas de ambos os grupos estudados. A concordância nas respostas de profissionais e usuários em relação aos aspectos tangíveis da prestação de serviços também foi observada por Castellanos (2002).

\section{Conclusões}

Este artigo indica, por meio do estudo, que para os clientes os aspectos mais significativos na percepção da qualidade em serviços públicos de odontologia, da Prefeitura Municipal de Florianópolis, são a tranquilidade ao utilizar os serviços e a clareza ao esclarecer dúvidas (91\%) e para os cirurgiões-dentistas é a boa execução dos serviços (100\%). Tal fato está de acordo com o encontrado na literatura, pois para os profissionais a qualidade técnica dos serviços é altamente significativa e para os clientes a qualidade interpessoal é mais significativa. De maneira geral, houve concordância nas respostas de ambos os grupos estudados.

Os elevados percentuais presentes nas respostas dos cirurgiões-dentistas e dos clientes permitem concluir que a percepção da qualidade em serviços públicos de odontologia pelos clientes e pelos profissionais pode ser verificada pelos fatores determinantes da qualidade investigados neste artigo.

$\mathrm{O}$ instrumento utilizado na pesquisa mostrou-se simples e efetivo para a coleta da opinião dos participantes sobre a percepção da qualidade em serviços de odontologia, o que permite acompanhar as mudanças que constantemente ocorrem nos valores, expectativas e desejos dos clientes que buscam, a cada dia, serviços de melhor qualidade.

Obter, perceber ou avaliar a qualidade nos serviços públicos de saúde implica lidar com a estrutura de valores da sociedade, pois o que varia, na verdade, são os critérios segundo os quais a qualidade é julgada. 
O conhecimento dessa percepção possibilita a elaboração de uma caracterização do serviço prestado, objetivando, por exemplo, subsidiar a construção dos instrumentos de avaliação para que seja possível correlacionar a qualidade percebida e a qualidade avaliada do serviço prestado. A avaliação permite que as organizações conheçam detalhadamente o seu desempenho, considerando os critérios de excelência. Não se trata apenas de organizar os serviços para a demanda, mas de ordená-los para as necessidades dos clientes que são e serão sempre sua razão de ser.

\section{Referências bibliográficas}

ABRAMS, R. A.; AYERS, C. S.; PETTERSON, M. V. Quality assessment of dental restorations: a comparison by dentists and patients. Community Dent. Oral Epidemiol, v. 4, p. 317-319, 1986.

ANSUJ, A. P.; ZENCKNER, C. L.; GODOY, L. P. Percepção da qualidade dos serviços de odontologia. In: ENCONTRO NACIONAL DE ENGENHARIA DE PRODUÇÃO, 25. Anais... Porto Alegre, 2005.

ASSADA, R. M. A equipe como vetor de qualidade. 2001. Disponível em: <www. odonto.com.br>. Acesso em: 20 jul. 2005.

CASTELLANOS, Pubenza López. Comparação entre a satisfação do usuário com os serviços oferecidos num hospital geral e a percepção gerencial dessa satisfação. 2002. 128 p. Dissertação (Mestrado) — Eaesp/FGV, São Paulo.

CERQUEIRA, J. P. de et al. Iniciando os conceitos de qualidade total. Biblioteca Pioneira de Administração e Negócios. São Paulo: Pioneira, 1994. Série Qualidade Brasil.

DONABEDIAN, A. Explorations in quality assessment and monitoring: the definition of quality and approaches to its assessment. Health Administration Press, v. 1, p. $163,1980$.

ESTEFANO, E. V. V. Satisfação dos recursos humanos no trabalho: um estudo de caso na biblioteca central da Universidade Federal de Santa Catarina. 1996. Dissertação (Mestrado em Engenharia) - Universidade Federal de Santa Catarina, Florianópolis.

FELDMAN, L. B. Como alcançar a qualidade nas instituições de saúde: critérios de avaliações, procedimentos de controle, gerenciamento de riscos hospitalares até a certificação. São Paulo: Martinari, 2004. 250 p.

GIANESI, I. G. N.; CORRÊA, H. L. Administração estratégica de serviços: operações para a satisfação do cliente. São Paulo: Atlas, 1996. 233 p. 
GRÖNROOS, C. Service management and marketing: managing the moments of truth in service competition. Lexington: Lexington Books, 1990.

LAS CASAS, A. L. Qualidade total em serviços: conceitos, exercícios e casos práticos. 3. ed. São Paulo: Atlas, 1999. 206 p.

LEÃO, A. T. T.; DIAS, K. Avaliação dos serviços de saúde prestados por faculdades de odontologia: a visão do usuário. Rev. Bras. Odont. Saúde Coletiva, v. 2, n. 1, p. 40-46, 2001.

LIMA, C. R. M. de. A avaliação do custo-eficácia das intervenções em organizações de saúde. Revista de Administração de Empresas, São Paulo, v. 38, n. 2, p. 62-73, abr./jun. 1998.

MALIK, A. M.; TELES, J. P. Hospitais e programas de qualidade no estado de São Paulo. Revista de Administração de Empresas, São Paulo, v. 41, n. 3, p. 51-59, jul./ set. 2001.

MUNRO, A. C. M. Divergências entre as expectativas do usuário e a percepção da gerência em relação a qualidade do serviço. 1994. Dissertação (Mestrado em Marketing) - UFRGS, Porto Alegre. Disponível em: <www.cesusp.ufrgs.br/PPGA/mktres. htm\#15 > . Acesso em: 20 abr. 2004.

NEVES, J. F; NEVES, M. C. P. Qualidade e sustentabilidade. Seropédica: Embrapa Agrobiologia, dez. 2000. 14 p.

PALADINI, E. P. Gestão da qualidade no processo: a qualidade na produção de bens e serviços. São Paulo: Atlas. 1995. 286 p.

REGIS FILHO, G. I.; LOPES, M. C. Estudo de clima organizacional em serviços ambulatoriais de saúde pública, da Secretaria de Saúde de Itajaí - SC. Segunda parte: perfil dos servidores e nível de satisfação. Rev. Cien. Saúde, Florianópolis, v. 15, n. 1-2, p. 163-190, jan./dez. 1996.

SLACK, Nigel et al. Administração da produção. São Paulo: Atlas, 1996.

VASCONCELLOS, P. P. de. Desenvolvimento de um modelo de avaliação da qualidade do serviço odontológico. 2002. 91 f. Dissertação (Mestrado em Engenharia de Produção) - Centro Tecnológico, Universidade Federal de Santa Catarina, Florianópolis.

VIEIRA, M. M. F. et al. Indicadores de qualidade na administração municipal: um estudo exploratório na prefeitura da cidade de Recife. RAC, v. 4, n. 1, p. 69-91, jan./abr. 2000.

VUORI, H. A qualidade da saúde. Cad. Ciência e Tecnologia, v. 3, p. 17-24, 1991.

ZEITHAML, V. A.; PARASURAMAN, A.; BERRY, L. L. Delivering quality service: balancing customer perceptions and expectations. New York: The Free Press, 1990. 226 p. 